\title{
СОЦИАЛЬНАЯ ЗАЩИТА МИГРАНТОВ КАК ФАКТОР СОЦИАЛЬНОЙ ИНТЕГРАЦИИ
}

\begin{abstract}
АНнотАция. В условиях усиления миграционных потоков на международном уровне остро встает вопрос об интеграции прибывающих трудовых мигрантов во все сферы общественной жизни принимающей страны. Трудовые мигранты зачастую предоставлены сами себе, лишены семейного окружения, у них ограничен доступ к информации, нет социальных связей. Одним из инструментов социальной интеграции может стать включение трудовых мигрантов в покрытие государственными программами социальной защиты населения. Расширение охвата трудовых мигрантов системой социальной защиты имеет ряд положительных преимуществ для принимающей страны, но при этом существуют и препятствия для реализации этой задачи. Основной проблемой в этой сфере является нелегальный статус значительной части трудовых мигрантов. С учетом современных тенденций в рамках международного сотрудничества система обязательного социального страхования Российской Федерации постепенно адаптирует свои условия для расширения охвата иностранных трудовых мигрантов.

кЛючЕВЫЕ слОВА. Трудовые мигранты; социальная интеграция мигрантов; социальная защита мигрантов.

ИНФОРМАЦИЯ О СТАТЬЕ. Дата поступления 28 мая 2016 г.; дата принятия к печати 9 июня 2016 г.; дата онлайн-размещения 22 июля 2016 г.
\end{abstract}

E. V. Ageeva Baikal State University, Irkutsk, Russian Federation

\section{SOCIAL PROTECTION OF MIGRANTS AS A FACTOR OF SOCIAL INTEGRATION}

\begin{abstract}
In terms of increasing migration flows at the international level there sharply arises the issue of integrating arriving migrants in all spheres of social life of the host country. Migrant workers are often left to themselves, deprived of the family environment, they have limited access to information, there are no social ties. One of the instruments of social integration may be inclusion of labor migrant into coverage by state programs of social public protection. Expanding the coverage of labor migrants by the social security system has a number of positive benefits for the host country, but there are also obstacles for implementing this task. Of the main problem in this area is the illegal status of a significant part of labor migrants. In terms of the current trends in the framework of international cooperation the system of compulsory social insurance in the Russian Federation is gradually adapting its facilities for expanding the coverage of foreign labor migrants.

KEYWORDS. Labor migrants; social integration of migrants; social protection of migrants. ARTICLE INFO. Received May 28, 2016; accepted June 9, 2016; available online July 22, 2016.
\end{abstract}

Одним из актуальных вопросов в сфере социальной политики Российской Федерации является вопрос о включении трудовых мигрантов в систему социальной защиты [1-12]. Причем данная проблема является острой для всего мирового сообщества. Численность международных трудовых мигрантов трудно оценить или подсчитать, особенно когда значительная их часть занята в неформальном секторе экономики. За пределами страны происхождения проживает примерно 232 млн чел.,

(C) E. В. Агеева, 2016

\section{Baikal Research Journal}

электронный научный журнал Байкальского государственного университета 
или 3,2 \% населения мира, которых и можно назвать международными мигрантами. Это свидетельствует о постоянном росте численности мигрантов за последние 25 лет - с 154 млн чел. в 1990 г. до 175 млн в 2000 г. ${ }^{1}$

Международный трудовой мигрант по определению Организации Объединенных наций - «лицо, которое будет заниматься, занимается или занималось оплачиваемой деятельностью в государстве, гражданином которого он или она не является». Международные работники-мигранты уезжают из своей страны для ведения трудовой деятельности на короткий или длительный срок, а также навсегда. Они могут представлять разные категории работников - домашние работники, работники сферы обслуживания, сельскохозяйственные работники, а также управляющие высшим звеном и высококвалифицированные работники формального сектора.

На 1 января 2015 г., по данным Государственного комитета статистики, численность прибывших в Российскую Федерацию из-за рубежа лиц старше 14 лет составила более 539 тыс. чел. Из них только 14 \% имеют высшее профессиональное образование, 21 \% - среднее специальное образование, а 23 \% уровень образования не указали. Из прибывших официально на трудоустройство приехали 35 \% , около половины в качестве основания для прибытия указали причины личного характера. Две трети прибывших мигрантов - мужчины, 90 \% которых трудоспособного возраста. Абсолютное большинство прибывших на территорию Российской Федерации в 2014 г. - жители стран СНГ (90\%). Лидерами по распределению иностранных граждан по территории РФ стали Центральный, Приволжский и Северо-Западный федеральные округа. При этом стало ясно, что основная цель большинства прибывающих из ближнего зарубежья иностранных граждан - это трудовая деятельность. Большинство этих граждан отмечает, что уровень жизни и трудового дохода в Российской Федерации выше, чем в их родных странах. Всего, по данным Федеральной миграционной службы, в России более 1,5 млн чел. имеют официальное разрешение на трудоустройство. Однако многие специалисты отмечают, что львиная доля трудовых мигрантов в России находится на территории страны нелегально. Современная система учета не имеет особого представления о месте их пребывания на территории страны и видах их активности.

Миграция приносит стране трудоустройства много положительных моментов: улучшение демографической ситуации, новые знания и умения, повышение производительности труда, дешевизна рабочей силы и т. д. Мигранты обладают умениями и навыками, которые могут отсутствовать или быть недостаточно развитыми в стране пребывания. Трудящиеся мигранты часто отличаются высоким уровнем предприимчивости и трудолюбия. В ряде стран трудящиеся мигранты - это экономически активные представители возрастной группы от 20 до 39 лет с оконченным и оплаченным образованием. Их средний возраст обычно ниже, чем средний возраст населения принимающей страны, что способствует ее демографическому омоложению.

Миграция также создает и проблемы, одной из которых является проблема социальной интеграции приезжих в общество принимающей страны. Трудовые мигранты зачастую предоставлены сами себе, лишены семейного окружения и вынуждены работать в новых незнакомых условиях, когда им может не хватать информации, неформальной поддержки и социальных связей. Жћенщины, особенно домашние работники, а также работники, занятые в неформальном секторе, молодежь, сезонные трудовые мигранты и нелегальные мигранты образуют особенно уязвимую к эксплуатации группу трудовых мигрантов. Трудовые мигранты часто заняты в неформальном секторе экономики, находятся вдали от дома и имеют ограниченный доступ к внешним механизмам поддержки. В отличие от коренных жителей трудоспособного

\footnotetext{
${ }^{1}$ Организация Объединенных Наций : офиц. сайт. URL : http://www.un.org.
}

\section{Baikal Research Journal}

электронный научный журнал Байкальского государственного университета 
возраста, трудовые мигранты часто не имеют доступа к дополнительным финансовым продуктам, таким как страхование жизни или пенсионные фонды. Это объясняется недостатком знаний, языковым барьером или тем, что поставщики финансовых услуг не рассматривают эту категорию работников как привлекательную (или надежную).

Государственная система социальной защиты в отношении трудовых мигрантов может стать действенным инструментом социальной интеграции их в общество принимающей страны и сокращения масштабов эксплуатации и угнетения этой группы лиц, поскольку оно принуждает формализовать трудовые отношения и предоставить работникам целый ряд социальных услуг.

К международным мигрантам, как правило, применяется подход, когда их по возможности включают в действующие программы, если они соответствуют определенным критериям, например, требованию к минимальному стажу, что позволяет сохранить за системой социального обеспечения на родине ответственность за трудовых мигрантов, приезжающих на короткий срок. В действительности, ввиду самых разных характеристик трудовых мигрантов ${ }^{2}$ к ним применяется целый ряд подходов:

1. Участие в базовой системе социального обеспечения принимающей страны. Это может требовать принятия дополнительных административных мер или изменения требований к накоплению и сохранению трудовых прав и минимальному трудовому стажу. Обычно этот подход гарантирует единообразное и равное обращение с работниками, выполняющими одну и ту же работу, и сохраняет за мигрантами право на получение пособий, когда они остаются в стране сверх установленного срока. Его недостатками являются возможное дробление прав, связанных с трудовым стажем, что требует принятия юридических и административных мер, направленных на оказание поддержки мигрантам, переезжающим из одной страны в другую, а также увеличение административных расходов принимающих стран (например, из-за требований к оформлению документов).

2. Отдельная программа для всех трудовых мигрантов, в рамках которой у всех работников-мигрантов равные условия участия. Хотя в ряде принимающих стран этот подход используется к определенным категориям работающих, к которым причисляется значительное число международных трудовых мигрантов (таким как самозанятые работники и работники неформального сектора).

3. Участие в системе социального обеспечения на родине. Таким образом эти лица сохраняют права на пособия, зависящие от непрерывности стажа, соответствия размера пособий потребностям семьи и отдельного работника.

Рассматривая интеграцию трудовых мигрантов в систему социальной защиты принимающей страны, можно столкнуться с проблемой прогнозирования их потоков и их качественных трудовых характеристик. Это затрудняет административное планирование и требует гибкости со стороны органов социального обеспечения. Кризис показал, что объем и направление потоков иммигрантов и эмигрантов могут быстро меняться, и поэтому трудно прогнозировать их будущую динамику. Однако факторы, ведущие к росту миграции, скорее всего, сохранятся в будущем, а именно доступность транспорта и связи, глобализация, гибкие рынки труда и вклад в повышение мобильности рабочей силы развития международного сотрудничества органов социальной защиты разных стран, например, путем подписания двусторонних и многосторонних соглашений.

Трудящиеся-мигранты должны участвовать в системах социальной защиты и социального страхования по целому ряду причин. Во-первых, необходимость защиты работника и его семьи от действия совокупности социальных рисков в течении всего жизненного цикла. Включение в сферу социальной защиты от социальных рисков -

${ }^{2}$ Справочник по расширению охвата работников-мигрантов социальным обеспечением. URL : www.issa.int.

\section{Baikal Research Journal}

электронный научный журнал Байкальского государственного университета 
это право, закрепленное Всеобщей декларацией прав и свобод человека. В ст. 22 Всеобщей декларации прав человека указано, что каждый человек, как член общества, для поддержания достоинства и свободного развития личности, имеет право на социальное обеспечение и на осуществление необходимых прав в экономической, социальной и культурной областях посредством национальных усилий и международного сотрудничества в соответствии со структурой и ресурсами каждого государства; т. е. государства, подписавшие декларацию, согласились с тем, что общество, в котором живет индивидуум, должно помогать ему развиваться и предоставить все преимущества (культурное, социальное обеспечение), предлагаемые в данной стране. Это понятие имеет другой смысл, чем российская «социальная защита», поскольку означает состояние защищенности, ощущение безопасности человека в обществе, а не деятельность государства и других общественных институтов. Социальная защищенность в западных странах реализуется через государственные программы, нацеленные на поддержку благосостояния населения с помощью мер, гарантирующих доступ к ресурсам, необходимым для обеспечения жизни и здоровья наиболее уязвимых слоев населения, таких как дети, пожилые, больные и безработные [1, с. 92].

Во-вторых, давно признано, что трудовая миграция приносит пользу для экономики принимающей страны и ее общества. Поэтому благоприятные условия социальной защиты мигрантов в принимающей стране играют особую роль не только в привлечении мигрантов в страну, но и в поддержке их производительности, защите их семей и устранении любых препятствий на пути их трудовой деятельности, что способствует решению широких задач на рынке труда и в экономике в целом. Развитая система социальной защиты, в равной степени распространяемая как на местных работников, так и на трудовых мигрантов, может способствовать сплочению общества. Равное и справедливое обращение со всеми работниками и недопущение маргинализации отдельных групп населения сокращает масштаб неравенства и, следовательно, социальную напряженность и угрозу конфликтов. При этом, участвуя на равных в финансировании системы социальной защиты путем уплаты налогов или взносов, трудовых мигрантов нельзя будет обвинить в злоупотреблении системой принимающей страны. Еще одной причиной для расширения охвата за счет трудовых мигрантов является способствование этого процесса формализации занятости мигрантов и включение их в формальный сектор экономики, что повысит собираемость налогов и уменьшит число работников, не защищенных нормами охраны труда. В принципе, труд в формальном секторе экономики должен привести к сокращению масштабов бедности и повысить стабильность занятости, хотя любые формы занятости можно «формализовать» только до определенных пределов.

Есть свои плюсы и для финансовой системы социальной защиты принимающей страны - это экономия на административных издержках за счет увеличения масштаба. Чем больше участников охватывает система социального обеспечения, тем выше ее административная эффективность и тем устойчивее к стрессам программа финансирования пособий.

К главным препятствиям на пути расширения охвата трудовых мигрантов социальной защитой относятся:

1. Затраты - независимо от того, как финансируются программы социального обеспечения (за счет взносов или налогов), социальная защита трудовых мигрантов предполагает расходы. При этом во многих случаях трудовые мигранты платят больше, чем получают. Это относится даже к программам социального обеспечения, которые полностью или частично финансируются за счет налоговых поступлений, поскольку трудовые мигранты участвуют и в их финансировании, например, платя потребительские налоги. В Швейцарии, по оценкам Швейцарской федерации бизнеса «Economie Suisse» и Швейцарской федерации работодателей, мигранты вносят 21 \% взносов в систему со-

\section{Baikal Research Journal}

электронный научный журнал Байкальского государственного университета 
циального обеспечения и получают 15 \% суммы всех пособий. При этом социальное обеспечение трудовых мигрантов, занятых в неформальном секторе, вызывает те же трудности, что и социальное обеспечение работников неформального сектора в целом.

2. Административные расходы - во многих случаях меры, направленные на обеспечение охвата трудящихся-мигрантов, приходится адаптировать под их особенности, и каждый новый участник программы может дорого ей обходиться. Поскольку многие мигранты заняты низкооплачиваемым трудом, удельные затраты на обработку каждого взноса относительно высоки, что может оказаться решающим фактором для стран с ограниченными государственными ресурсами и ограниченным финансированием системы социального обеспечения.

3. Негативное восприятие миграции общественностью принимающей страны. Социальное обеспечение трудящихся-мигрантов зачастую становится чувствительным вопросом политики, особенно во время экономического спада, когда отношение к мигрантам меняется в худшую сторону. Его подстегивают количественные оценки отрицательных последствий миграции, например, давление на размер оплаты труда в сторону ее понижения, а также неподтвержденные и единичные примеры, когда труд местных работников якобы вытесняет дешевый труд иммигрантов или когда трудовых мигрантов обвиняют в злоупотреблении системой социального обеспечения «себе во благо». Все больше сообщений о незаконном ввозе иммигрантов, зачастую с трагическими последствиями, вызывают споры о том, не поощряет ли социальная защита прибытие других нелегалов.

Таким образом, расширение социального обеспечения на трудовых мигрантов способствует более эффективному выполнению системами социальной защиты своей защитной функции, а также стимулирует экономический рост и укрепляет сплоченность общества. В то же время системы социальной защиты могут играть важную роль в решении проблем, связанных с трудовой миграцией: например, они способствуют социальной интеграции и, в случае постепенного расширения охвата трудящихся-мигрантов и формализации их занятости, принимают конкретные меры по смягчению рисков стагнации и снижения размера зарплаты, вызванных социальным демпингом и подобными последствиями миграции.

Включение трудовых мигрантов в программы социального обеспечения часто сопряжено с определенными проблемами для самих органов социальной защиты. Некоторые характеристики, присущие трудовым мигрантам (короткий трудовой стаж в принимающей стране и частая смена работы, занятость в неформальном секторе экономики, оторванность от находящихся на их иждивении членов семьи и т. д.) создают трудности учета и взаимодействия с ними. На них в меньшей степени распространяется традиционное правоотношение между работником и работодателем, на котором основаны, в частности, многие системы социального страхования. Охват данной категории работников зачастую связан с соблюдением сложных административных правил, которые могут требовать координации с другими ведомствами, часто находящимися за границей, сложной системы учета персональных данных и данных об уплате взносов работниками-мигрантами, а также информационной поддержки на разных языках.

Еще одной сложностью является и то, что работники-мигранты часто заняты в неформальном секторе и в целом имеют более короткий трудовой стаж. Это естественным образом сказывается на размере их будущих пособий в системах социального страхования (например, в системах с относительно высокими требованиями к минимальному трудовому стажу, периоду проживания в стране или продолжительности уплаты взносов), на возможности перевода пособий и прав в систему социальной защиты страны происхождения и на роли работодателя в сборе и уплате социальных взносов.

Сам объем и характеристики трудовой миграции трудно прогнозировать. Исследования показывают, что в условиях экономического спада трудовые мигранты,

\section{Baikal Research Journal}

электронный научный журнал Байкальского государственного университета 
как правило, страдают в первую очередь, а нестабильность миграционных потоков затрудняет управление и планирование деятельности с ними органов социальной защиты. Часто бывает особенно трудно обеспечить охват этой категории из-за культурных и языковых различий. Нехватка персональных данных о трудящихся-мигрантах в национальных базах данных может приводить к тому, что они не получают той же поддержки, что и граждане принимающей станы.

В связи с этим в настоящее время в мировом сообществе активно обсуждаются вопросы по развитию в странах происхождения мигрантов добровольных программ социальной защиты и социального страхования для них. Например, такие программы уже развиты для трудящихся-мигрантов в Сальвадоре и Мексике. В Сальвадоре $21 \%$ семей получают денежные переводы от работающих за рубежом. В стране действует добровольная программа «Особый режим» для трудящихся мигрантов. Ежемесячный взнос составляет 68,57 дол. США (т. е. 10 \% от условной месячной зарплаты в размере 685 дол. США). Пособия включают полное медицинское обслуживание семьи (работника, его супруги и детей моложе 12 лет). Примечательно, что в программе широко используются информационно-коммуникационные технологии, партнерские связи с объединениями граждан Сальвадора, живущих за рубежом, и помощь со стороны консульств. Чтобы оценить привлекательность программы, был проведен опрос, в ходе которого свыше половины респондентов (52 \% ) заявили о готовности платить предложенные взносы, однако их готовность зависела от того, на кого из членов семьи будет распространяться действие программы. Только 19 \% респондентов выразили готовность участвовать поодиночке. Интересно, что готовность платить взносы практически не зависит от их размера; при уменьшении взноса ниже 30 дол. США в месяц доля респондентов, готовых платить взносы, повысилась незначительно (с 52 до 63 \% ). В Мексике программа социальной защиты предусматривает добровольное участие мексиканских граждан, легально или нелегально работающих за рубежом, а также иностранцев, занятых на временных работах в стране ${ }^{3}$.

На сегодняшний день в России пространство социальной политики сужается до рамок поддержки социально уязвимых слоев населения [2]. Социальная защита в узком смысле понимается как система мер по поддержке людей, оказавшихся, в силу определенных обстоятельств, в трудной жизненной ситуации. Под влиянием либеральной парадигмы «невидимой руки рынка» российское государство минимизирует свое вмешательство в жизненно важные общественные процессы создания и поддержки условий, способствующих личностному формированию и успешной жизнедеятельности граждан [3, с. 94]. До 2015 г. в законодательстве Российской Федерации, посвященном вопросам обязательного социального страхования, права лиц, временно пребывающих на территории страны, были значительно ограничены в связи с их временным статусом. Однако в настоящее время российское законодательство в этой сфере претерпело определенные изменения. Практически полный социальный пакет по обязательному социальному страхованию трудовые мигранты получают при условии легальной занятости на условиях трудового договора.

С 2015 г. из законов, посвященных социальному страхованию, ушло большинство различий в отношении застрахованных лиц с разным статусом пребывания в Российской Федерации. Исключением остается система обязательного медицинского страхования. В отношении этих групп граждан вводится обязанность по приобретению полисов добровольного медицинского страхования для обеспечения гарантий на получение неотложной медицинской помощи. В сфере обязательного пенсионного страхования Пенсионный Фонд РФ активно проводит мероприятия по заключению двухсторонних соглашений, позволяющих трудовым мигрантам учитывать заработанные пенсионные права как в стране происхождения, так и в стране трудоустройства.

\footnotetext{
${ }^{3}$ Справочник по расширению охвата работников-мигрантов социальным обеспечением.
}

\section{Baikal Research Journal}

электронный научный журнал Байкальского государственного университета 
Как отмечается в годовом отчете Пенсионного фонда РФ, сотрудничество России с другими государствами в области взаимного пенсионного обеспечения в основном строится на договорах двух типов: территориальном и пропорциональном. Согласно первому приобретенные в России пенсионные права учитываются при назначении пенсии за границей, но сама пенсия при этом назначается по законодательству иностранного государства и за его счет. По договору пропорционального принципа каждая страна финансирует приобретенные на ее территории пенсионные права независимо от того, по законодательству какой страны назначается пенсия. Большинство договоров России с другими странами в области пенсионного обеспечения основано на пропорциональном принципе. Такие договоры заключены в основном с бывшими республиками СССР, с которыми происходят активные миграционные процессы. Договоры по территориальному принципу постепенно уходят из практики применения, поскольку перестали отвечать современным требованиям систем социального обеспечения государств. В 2015 г. действовали 16 международных договоров, регламентирующих отношения России в области пенсионного обеспечения с 20 государствами.

С учетом возрастающего значения трудовой миграции для развития экономики и учитывая проблему охвата растущего числа трудовых мигрантов и их уязвимость (особенно работников неформального сектора), следует наращивать усилия в этом направлении. Однако значительный успех возможен лишь там, где политические инициативы государства сочетаются с эффективным администрированием. В современных политических условиях социальная защита трудовых мигрантов и условия ее предоставления может внести важный вклад в повышение авторитета государства, особенно когда к нему приковано внимание международной общественности.

\section{Список использованной литературы}

1. Метелева Е. Р. Определение ключевых терминов в социальной сфере / Е. Р. Метелева // Известия Иркутской государственной экономической академии. $-2016 .-$ T. 26, № 1. C. 90-98. - DOI : 10.17150/1993-3541.2016.26(1).90-98.

2. Межстрановый обмен мнениями по проблемам социального здоровья иностранных трудовых мигрантов / Ю. Г. Лаврикова [и др.] // Журнал экономической теории. - 2014. № 2. - C. $150-152$.

3. Аблажей Н. Н. Масштабы экономической миграции и натурализации киргизских мигрантов в Сибирском федеральном округе в 2001-2012 гг. / Н. Н. Аблажей, А. С. Турдуева // ЭКО. Всероссийский экономический журнал. - 2014. - № 8. - С. 43-51.

4. Социальная политика региона: теория и практика : учеб. пособие / под ред. И. П. Скворцова. - М. : КноРус, 2010. -448 с.

5. Яковлева Н. Как Америка получает рабочую силу / Н. Яковлева ; коммент. И. Воронецкого // Трудовое право. - 2014. - № 1. - С. 117-120.

6. Василишина Н. В. Негативные последствия экономического кризиса и проблемы деятельности Международной организации труда / Н. В. Василишина // Известия Иркутской государственной экономической академии. -2011 . - № 6 (80). - С. 171-174.

7. Докторович А. Б. Воспроизводство социального и человеческого потенциалов / А. Б. Докторович // Труд и социальные отношения. - 2010. - № 1. - С. 11-17.

8. Ивахнюк И. Управление международной трудовой миграцией: мировой опыт и российские практики / И. Ивахнюк // Проблемы теории и практики управления. - 2015. № $10 .-$ C. $36-44$.

9. Малахов В. С. Интеграция мигрантов как административная проблема: опыт Евросоюза / В. С. Малахов // Мировая экономика и международные отношения. - 2015. — № 1. - С. 77-87.

10. Ржаненков А. Н. Социальная защита населения: достижения года минувшего и перспективы совершенствования / А. Н. Ржаненков // Социальное обслуживание. - 2013. № 3. - C. 9-22.

11. Пономарева Т. Россия ратифицировала конвенции МОТ: что дальше? [Электронный ресурс] / Т. Пономарева // Кадровое дело. - 2010. - № 8. - Режим доступа : http://www. audit-it.ru/articles/account/a1/247640.html.

\section{Baikal Research Journal}

электронный научный журнал Байкальского государственного университета 
12. Flores L. Social security and migration : Conference paper / L. Flores // 27th General Assembly of the CISS, San Salvador, 24-26 June. - San Salvador, 2013.

\section{References}

1. Meteleva E. R. Defining the key terms of social welfare. Izvestiya Irkutskoy gosudarstvennoy ekonomicheskoy akademii = Bulletin of Irkutsk State Economics Academy, 2016, vol. 26, no. 1, pp. 90-98. DOI: 10.17150/1993-3541.2016.26(1).90-98. (In Russian).

2. Lavrikova Yu. G.et al. Intercountry Exchange of Opinions on Problems of Social Health of Foreign Labor Migrations. Zhurnal ekonomicheskoi teorii = Journal of Economic Theory, 2014, no. 2, pp. 150-152. (In Russian).

3. Ablazhei N. N., Turduyeva A. S. Scales of the Economic Migration and Naturalisation of the Kyrgyz Migrants in the Regions of the Siberian Federal District in 2001-2012. EKO. Vserossiiskii ekonomicheskii zhurnal =ECO, 2014, no. 8, pp. 43-51. (In Russian).

4. Skvortsov I. P. (ed.). Sotsial'naya politika regiona: teoriya i praktika [Social regional policy: theory and practice]. Moscow, KnoRus Publ., 2010. 448 p.

5. Yakovleva N.; Voronetsky I. (ed.). How America gets labor power. Trudovoe pravo=Labor Law, 2014, no. 1, pp. 117-120. (In Russian).

6. Vasilishina N. V. Adverse effects of economic crisis and problems of International Labour Organization Activity. Izvestiya Irkutskoy gosudarstvennoy ekonomicheskoy akademii = Bulletin of Irkutsk State Economics Academy, 2011, no. 6 (80), pp. 171-174. (In Russian).

7. Doktorovich A. B. Reproductions of social and human potentials. Trud i sotsial'nye otnosheniya $=$ Labour and Social Relations, 2010, no. 1, pp. 11-17. (In Russian).

8. Ivakhnyuk I. International labour migration management: global experience and Russian practices. Problemy teorii i praktiki upravleniya = Problems of Theory and Practice of Management, 2015, no. 10, pp. 36-44. (In Russian).

9. Malakhov V. S. Immigrants Integration as an Administrative Problem: the Case of the European Union. Mirovaya ekonomika i mezhdunarodnye otnosheniya $=$ World Economy and International Relations, 2015, no. 1, pp. 77-87. (In Russian)

10. Rzhanenkov A. N. Social protection of the population: achievements of the last year and prospects of improvement. Sotsialnoe obsluzhivanie = Social Service, 2013, no. 3, pp. 9-22. (In Russian).

11. Ponomareva T. Russian has ratified the conventions of ILO: what comes next. Kadrovoe delo = Personnel Records Management, 2010, no. 8. Available at: http://www.audit-it.ru/articles/account/a1/247640.html. (In Russian).

12. Flores L. Social security and migration (Conference paper). 27th General Assembly of the CISS, San Salvador, 24-26 June. San Salvador, 2013.

\section{Информация об авторе}

Агеева Евгения Валерьевна - кандидат экономических наук, доцент, кафедра страхования и управления рисками, Байкальский государственный университет, 664003, г. Иркутск, ул. Ленина, 11, e-mail: ageeva-ev@isea.ru.

\section{Author}

Evgeniya V.Ageeva - PhD in Economics, Associate Professor, Chair of Insurance and Risk Management, Baikal State University, 11 Lenin St., 664003, Irkutsk, Russian Federation; e-mail: ageeva-ev@isea.ru.

\section{Библиографическое описание статьи}

Агеева Е. В. Социальная защита мигрантов как фактор социальной интеграции / Е. В. Агеева // Baikal Research Journal. - 2016. — T. 7, № 4. - DOI : 10.17150/2411$\underline{6262.2016 .7(4) .6 .}$

\section{Reference to article}

Ageeva E. V. Social protection of migrants as a factor of social integration. Baikal Research Journal, 2016, vol. 7, no. 4. DOI : 10.17150/2411-6262.2016.7(4).6. (In Russian).

\section{Baikal Research Journal}

